\title{
CRITÉRIO TEMPORAL DO IMPOSTO SOBRE A HIERANÇA
}

\author{
Bruno Nogueira Rebouças \\ Aluno do curso de Direito da FA7, orientado pelo prof. dr. Hugo de \\ Brito Machado Segundo (UFC/FA7) \\ rebbruno@gmail.com
}

Sumário: Introdução. 1. Fundamentos do ITCMD. 2. O ITCMD e a Constituição Federal de 1988. 3. O princípio Saisine. 4. O fato gerador do ITCMD. 5. O Código Civil de 1916 e a transmissão causa mortis. 6. Visão jurisprudencial do assunto. 7. A personalização do imposto causa mortis. 8. Decadência em direito tributário. 9. O prazo decadencial no imposto sobre herança. Considerações finais. Referências.

Resumo: O presente trabalho aborda o critério temporal, o qual determina o fato gerador do imposto de transmissão causa mortis e suas respectivas repercussões no âmbito jurídico, apreciando o fenômeno de personalização do dito tributo e suas derivações. O princípio francês de raízes medievais denominado saisine é centro de boa parte das discussões acerca do tema proposto, desencadeando, também, diferentes questionamentos os quais carecem de respostas. Por fim, a questão do momento a partir do qual devem ser contados os prazos decadenciais para efeito de lançamento do imposto se perfaz com o desencadear do referido tema, o que, inexoravelmente, só pode ser analisado diante de uma coordenação e harmonização com a legislação civil e seus institutos, a fim de se ver o ordenamento jurídico funcionando como um sistema que inevitavelmente deve ser interpretado como tal, sendo-lhe inerente essa imposição.

Palavras-chave: Direito Tributário. Imposto. Herança. Fato Gerador. Critério Temporal.

\section{INTRODUÇÃO}

Pouco exploradas pela doutrina são as questões que envolvem o fato gerador do imposto sobre a herança (ITCMD), nitidamente no que se refere ao seu aspecto temporal, e ao correlacionado prazo decadencial de lançamento do tributo pela Fazenda Pública. Destaque-se, no entanto, trabalho monográfico desenvolvido por Clayton Eduardo Prado (2009), o qual sintetiza os principais pontos referentes ao tratamento desse tributo hoje, em nosso país. No presente trabalho, será dado um enfoque especial às interpretações dadas pelos tribunais superiores sobre o assunto, invocando-se, para a fundamentação da primeira questão, o denominado 
Princípio Saisine, famigeradamente aplicado ao Direito das Sucessões em nosso país. Questões mais delicadas, como a determinação do momento a partir do qual será contado o prazo decadencial já mencionado, serão tratadas ao fim do estudo aqui desenvolvido, representando tema da segunda questão proposta. É de nítida relevância se considerar que, embora didaticamente separadas em nossa argumentação, estão longe de estarem separadas as conclusões que serão extraídas de ambas as questões, haja vista, como já foi dito, a correlação necessária tanto dos fatos como dos direitos que lhes são consequentes. Resumidamente podemos assim dizer: não poderíamos nos questionar acerca do prazo decadencial para exigência do tributo pelo Erário, sem antes encobrir a análise do tema referente ao aspecto temporal do fato gerador do tributo em enfoque. No que pese a obviedade da proposição, a intenção preliminar desse trabalho é ressaltar a importância desses tópicos, que evidentemente se vinculam por seu comum aspecto temporal, o que será alvo de nosso estudo.

Este artigo não pretende chegar a soluções definitivas sobre o tema, abrindo espaço também para novas ideias que envolvem os assuntos aqui tratados e novos questionamentos que acabem por abrandá-los ou pormenorizá-los por fim.

\section{Fundamentos do ITCMD}

No que pese o fato de que, no referido imposto, passou a figurar, em seu âmbito de incidência, a doação, trataremos inicialmente de sua forma inicial, a qual não possuía essa previsão, reduzindo inicialmente nossa análise ao dito imposto de transmissão causa mortis. ${ }^{1}$

A tributação sobre a herança existe desde a Antiguidade, perpassando por vários momentos históricos, com diversificadas formas de tratamento.

Historicamente, a tendência anterior era a de os impostos sobre a herança serem cobrados sobre o acervo hereditário indiviso² (espólio indiviso), o que tendia a despersonalizar o patrimônio tributado, tendendo a ignorar-se a capacidade econômica dos herdeiros para efeitos de tributação. No entanto, como atestara Baleeiro,

Mas alguns países iniciaram outro critério mais racional e justo: o da aplicação sobre o líquido dos quinhões e legado. Esse critério veio a coincidir com a tendência a considerar-se tal imposto como tributo de caráter direto e pessoal sobre o herdeiro, e não o imposto real sobre o monte ou espólio. (Baleeiro, 2010, p. 478)

\footnotetext{
${ }^{1}$ Assim versava a Constituição de 1969: Art. 23. Compete aos Estados e ao Distrito Federal instituir impostos sobre: I - transmissão, a qualquer título, de bens imóveis por natureza e acessão física e de direitos reais sobre imóveis, exceto os de garantia, bem como sobre a cessão de direitos à sua aquisição; [....]

${ }^{2}$ Não que esse termo ou semelhante houvesse sido sempre usado.
} 
Em vários pontos mostraram-se argumentos favoráveis à existência desse tipo de imposto, o que aqui referenciá-los seria um modo de desfocar a finalidade deste trabalho.

Por ilustração, pode-se destacar a importância que foi dada ao imposto de herança (assim como a outros) por Keynes com o fim de a Política Fiscal buscar uma igualdade de distribuição de renda, influindo, consequentemente, na propensão ao consumo. Desta forma trata o autor:

Os impostos sobre a renda, particularmente quando gravam a renda "não ganha", os impostos sobre lucros de capital, sobre heranças etc., são tão importantes quanto a taxa de juros, sendo mesmo possível que as modificações eventuais da política fiscal tenham, pelo menos nas expectativas, maior influência que a própria taxa de juros. Se a política fiscal for usada como um instrumento deliberado para conseguir maior igualdade na distribuição de rendas, seu efeito sobre o aumento da propensão a consumir será, naturalmente tanto maior. (Keynes, 1982, p. 87)

\section{O ITCMD E A CONSTITUiÇão Federal de 1988}

Assim versa o art. 155, inciso I, da Constituição Federal:

Art. 155. Compete aos Estados e ao Distrito Federal instituir impostos sobre:

I - transmissão causa mortis e doação, de quaisquer bens ou direitos.

$[\ldots .]^{3}$

Aqui se acrescentam os bens móveis, e não só os imóveis, tal como era previsto na carta constitucional anterior. Embora mais restrito, visto que não abrange as transmissões inter vivos onerosas para efeito de competência dos Estados (há imposto próprio de competência municipal para bens imóveis), abrange, agora, a transmissão de propriedade de bens móveis. Veja-se que o ITCMD não abrange a transmissão onerosa, para qual estão previstos os seguintes impostos: o ITBI (de competência municipal), para transmissão de bens imóveis, e o ICMS, para coisa móvel que se destina ao comércio. Como lembra Machado Segundo (2010, pp. 191 e 192): "Na hipótese de coisa móvel não destinada ao comércio (p. ex., venda eventual de um relógio entre dois "particulares" não comerciantes), não há incidência de nenhum desses impostos."

Em síntese, procurou a Constituição atual afastar o caráter da onerosidade para fins de configuração desse imposto. Uma relevante causa da inclusão dos bens móveis na previsão do imposto deve-se ao fato da mudança da realidade social, que vem demonstrando a existência, cada vez mais comum, de fortunas de caráter mobiliário.

${ }^{3}$ Disponível em: $<$ http://www.planalto.gov.br/ccivil_03/constituicao/constitui\%C3\%A7ao.htm>. Acesso em: 19 de abril de 2011. 
Por fim, a transmissão dos direitos já vinha sendo prevista na Carta anterior, mas o legislador constitucional não repetiu expressamente o preceito que excetuava os direitos de garantia, o que não impede de se continuar com tal interpretação à luz da nova Constituição. (Baleeiro, 2010, p. 259) ${ }^{4}$ Lembre-se ainda que prevê o texto constitucional que será de competência do Senado Federal afixar as alíquotas máximas a serem legalmente previstas e cobradas pelos Estados (ou Distrito Federal), o que impede sua cobrança, segundo melhor interpretação, anterior ou acima do patamar máximo fixado pela câmara maior.

É válido ainda lembrar que o sistema tributário adotado em nossa Constituição vê-se incompatível com a tributação simultânea do ITCMD e do imposto sobre a renda, no que pese ambos representarem, economicamente, acréscimos patrimoniais de indivíduos.

\section{O PrincíPIo SAISINE}

Analisando a definição dada à sucessão, pode-se dizer que se trata de "transmisión del património de uma persona fallecida a una o varias personas vivas. Se dice, en este sentido, que uma persona 'sucede a outra'." (Ripert e Boulanger, 1963/1965, p. 9)

O princípio Saisine determina que a transmissão da propriedade dá-se instantaneamente, no momento da morte do indivíduo, em relação aos seus herdeiros. Não há necessidade de manifestação de nenhum dos herdeiros para que tal princípio se processe, haja vista que o intuito perseguido seria o de que a transmissão dos bens do de cujus se daria independente de qualquer manifestação volitiva por parte dos destinatários da herança. Tendo sido acolhido pelo Código Civil de 2002:

Art. 1784. Aberta a sucessão, a herança transmite-se, desde logo, aos herdeiros legítimos e testamentários. ${ }^{5}$

Observe-se o fato de que o início da sucessão e, consequentemente, da transmissão da herança se dão no momento da morte do indivíduo, sendo irrelevante que os herdeiros, legítimos ou testamentários, tomem conhecimento do óbito, para que tal processo se efetue.

Como ensinara Pontes de Miranda, ao comentar o artigo 1572 do C.C. de 1916, o qual expunha o princípio Saisine (como por ele é chamado) no direito brasileiro:

\footnotetext{
${ }^{4}$ Nota de Misabel Abreu Machado Derzi sobre a não tributação pelos municípios da transmissão de direitos reais de garantias sobre imóveis, presente em Baleeiro (2010).

${ }^{5}$ Disponível em: <http://www.planalto.gov.br/ccivil/leis/2002/L10406.htm>. Acesso em: 19 abr. 2011.
} 
A regra jurídica há de ser lida como lá estivesse escrito: "Morto o de cujo, qualquer titularidade de direito transmissível a causa de morte e a posse transmitem-se aos herdeiros, legítimos ou testamentários". (Miranda, 1968, p. 17)

E, também,

Instituída herdeira qualquer entidade de direito privado ou público, desde que já personificada, a herança insere-se automaticamente no patrimônio da pessoa jurídica. O que pode ocorrer é que ela renuncie à herança; mas, aí, tudo se passa como a respeito de qualquer pessoa física. (IDEM, p. 18)

Ao contrário do que se possa imaginar, a dita aceitação da herança possui caráter meramente confirmativo de propriedade ou posse do acervo hereditário. (Diniz, 2005, p. 66)

A fim de demonstrar a importância do conceito de transmissão para fins de delineamento constitucional da competência tributária estabelecida para o ITCMD, ressalte-se a importância da preservação dos conceitos albergados implícita ou explicitamente pela Constituição Federal à época de sua formulação (ou decorrendo de emendas ao seu texto original), para efeitos de interpretação respeitosa aos parâmetros delineados pela Carta Magna. Como ensina o professor Hugo de Brito Machado:

Admitir que a lei ordinária redefina conceitos utilizados por qualquer norma da Constituição é admitir que a lei modifique a Constituição. É certo que a lei pode, e deve, reduzir a vaguidade das normas da Constituição, mas, em face da supremacia constitucional, não pode modificar o significado dessas.(Machado, 2010, p. 118)

Visto isso, faz-se necessário explorar, no direito privado, tanto o conceito de transmissão quanto o momento de sua configuração, para que se determine o aspecto temporal do fato gerador do tributo aqui tratado, vinculandose tal interpretação, irremediavelmente, à análise do artigo 1784 do C.C. vigente, o qual nos confirma o acolhimento do Princípio Saisine.

Não obstante o demonstrado, argumentações que não fogem de incoerência científica, insistem, mesmo admitindo que vão de encontro a toda a doutrina civilista, que o que caracteriza o fato gerador do imposto causa mortis seria a aceitação, não a morte e abertura da sucessão. Traz essa contraditória doutrina que "Por transmissão, entenda-se a transferência de bens ou direitos do patrimônio de um sujeito para o de outro, ou melhor, a mudança da titularidade de bem ou direito, por ato entre vivos ou por força da morte." (Correia Neto, 2011, p. 81)

E, depois, argumenta que

[.... aceitar tal exegese implicaria concluir que o Estado brasileiro autoriza tributação da morte, um fato da natureza, certo e inevitável, que, por si só nem 
mesmo revela riqueza. Dessa forma, estar-se-ia ferindo o princípio da capacidade contributiva, que determina que a escolha dos fatos geradores devem levar em conta somente os fatos que denotem patrimônio, renda ou consumo. (2011, p. 87)

Observemos que, quanto à primeira sentença, parece, em princípio, coerente o ponto de vista do autor; mas, quanto à segunda, parece que toda a coerência vai para o espaço, o que pode ser verificado pela confusão por ele feita ao confundir o fato gerador com a simples morte, quando, em verdade, o fato imponível estaria, sim, a se relacionar com a transmissão do patrimônio (auferível economicamente, embora não de forma imediata), que se dá com e a partir da abertura da sucessão. A morte é o simples marco temporal que determina o exato momento da abertura da sucessão, segundo o direito civil brasileiro. A progressiva personalização do imposto, que será tratada mais adiante, parece ter confundido a cabeça do referido autor, o que não faz autorizar, em nenhuma hipótese, que o intérprete ignore o significado dos termos albergados pelo texto constitucional, indo de encontro à própria Constituição.

\section{O Fato Gerador do ITCMD}

Como aqui já foi trabalhado, o fato gerador do imposto é a transmissão, causa mortis ou por doação, de bens ou direitos, excluindo-se os direitos de garantia, tais como a hipoteca, a anticrese etc. Para que o fato gerador do tributo se configure validamente para fins de cobrança, é necessário o prévio estabelecimento de alíquota máxima por resolução do Senado Federal. Sem tal afixação, vê-se inconstitucional a referida cobrança.

Esse fato pode ser exemplificado em caso concreto. Seguindo lições de Schubert Machado:

Tão logo entrou em vigor o novo Sistema Tributário, o Estado do Ceará tratou de instituir o seu Imposto de Transmissão Causa Mortis e doação, e o fez através da Lei Estadual n. ${ }^{\circ} 11.527 / 88$. Isso antes mesmo que o Senado fixasse as alíquotas máximas desse imposto. Por essa razão, o Estado utilizou de peculiar técnica legislativa e tratou das alíquotas do ITCD por remissão aos limites estabelecidos pelo Senado.

O princípio da estrita legalidade tributária, todavia, impõe como condição inafastável para que um imposto seja validamente instituído, que a LEI estabeleça desde logo todos os seus elementos essenciais, ou seja, devem estar contidos no texto da lei a alíquota, a base de cálculo e o contribuinte do imposto, assim como tudo que seja necessário para que, com a leitura do texto legal se possa chegar ao valor do imposto. Não pode, portanto, uma lei instituidora de imposto deixar de fixar clara e precisamente a alíquota do mesmo, sob pena de não instituí-lo, visto que em direito tributário não existem as chamadas "normas em branco." Para contornar esse problema e cobrar o referido imposto ainda em 1989, a Secretaria da Fazenda do Estado entendeu que poderia utilizar a alíquota máxima 
então fixada pelo Senado para o antigo ITBI, que era de 4\%, preenchendo a lacuna da lei estadual. E isso foi feito. O ITCD passou a ser cobrado com alíquotas que variavam de $2 \%$ a $4 \%$.

No que pese o ocorrido, o Senado Federal, em 1992, trouxe a esperada resolução, que fixava como alíquota máxima para o ITCM 8\%. O fisco começou a cobrar, arbitrariamente, não importando estar cobrando anteriormente alíquota máxima de $4 \%$, a alíquota máxima fixada pelo Senado, mesmo sem previsão por lei ordinária do Estado, o que se viu prática abusivamente reiterada. Tal atitude levaria ao pensamento equivocado de que não se necessitaria mais de lei ordinária determinando a instituição ou majoração do tributo, o que fere frontalmente o princípio da estrita legalidade, assim explicada por Paulo de Barros Carvalho:

O veículo introdutor da regra tributária no ordenamento há de ser sempre a lei (sentido latu), porém o princípio da estrita legalidade diz mais do que isso, estabelecendo a necessidade de que a lei adventícia traga no seu bojo os elementos descritores do fato jurídico e os dados prescritores da relação obrigacional. (Carvalho, 2007, p. 166 e 167)

Nesse aspecto, a previsão da alíquota em lei ordinária se perfaz estritamente indispensável para a válida cobrança do imposto, cabendo no contrário a devida e integral restituição do indébito.

Outro problema que surgiu posteriormente, nesse mesmo Estado, foi o que envolvia a efetiva criação pelo ente tributante, anos depois, de lei prevendo alíquota que não extrapolava o patamar máximo delimitado pelo Senado. Assim versa a lei n. 13.417 de 30 de dezembro de 2003 quanto às alíquotas:

Art. $1^{\circ}$. Esta Lei dispõe acerca do Imposto sobre Transmissão Causa Mortis e Doação, de quaisquer bens ou direitos - ITCD, a que se refere o art. 155, inciso I, da Constituição Federal.

[....]

\section{CAPÍTULO VI}

\section{DAS ALÍQUOTAS E DA APURAÇÃO DO IMPOSTO}

Art. 10. As alíquotas do Imposto sobre Transmissão Causa Mortis e Doação são:

a) nas transmissões causa mortis:

1. até 5.000 (cinco mil) Ufirces, $2 \%$ (dois por cento);

2. acima de 5.000 (cinco mil) e até 15.000 (quinze mil) Ufirces, 4\% (quatro por cento);

3. acima de 15.000 (quinze mil) e até 40.000 (quarenta mil) Ufirces, $6 \%$ (seis por cento); e

4. acima de 40.000 (quarenta mil) Ufirces, $8 \%$ (oito por cento);

\footnotetext{
${ }^{6}$ MACHADO, Schubert de Farias. A Alíquota Máxima Do Imposto De Transmissão Causa Mortis E

Doação No Estado Do Ceará. Disponível em: < http:// www.machado.adv.br//>
} 
b) nas transmissões por doação:

1. até 25.000 (vinte e cinco mil) Ufirces, $2 \%$ (dois por cento);

2. acima de 25.000 (vinte e cinco mil) Ufirces, $4 \%$ (quatro por cento).

$\S \mathbf{1}^{\mathbf{0}}$. A apuração do imposto devido será efetuada mediante a decomposição em faixas dos valores totais dos bens e direitos transmitidos que será convertido em Ufirce ou outro índice que venha a substituí-la, sendo que a cada uma das faixas será aplicada a respectiva alíquota.

$\S \mathbf{2}^{\mathbf{0}}$. As alíquotas deste imposto serão definidas com base no resultado da soma do valor venal da totalidade dos bens e direitos transmitidos, inclusive na hipótese de liberação de parte dos bens do espólio, por meio de autorização ou alvará judicial.

$\S 3^{\circ}$. A alíquota aplicável será:

I - nas transmissões causa mortis, aquela vigente na data da abertura da sucessão;

II - nas transmissões do fiduciário para o fideicomissário, aquela vigente no momento da transmissão;

III - nas transmissões por doação, aquela vigente no momento da transmissão.

$\S \mathbf{4}^{\mathbf{0}}$. O valor total do imposto devido será calculado mediante a soma dos valores parciais apurados na forma dos itens da alínea "a" ou "b", conforme se trate de transmissão causa mortis ou por doação, respectivamente. (Ribeiro Neto, 2011, p. 1155)

Veja-se, portanto, que agiu corretamente o legislador ao prever em lei do Estado a alíquota a ser validamente cobrada. O problema se relaciona, no entanto, à possível configuração de fato gerador anterior à nova lei, não podendo ela retroagir para cobrar tributo de quem não deve. Um exemplo interessante seria o caso de o indivíduo ter falecido anteriormente à lei de 2003, sabendo que a morte, como já vimos (Princípio Saisine), configura o aspecto temporal do fato gerador do tributo. Nesse caso, a cobrança, por exemplo, de alíquota de $6 \%$ seria flagrantemente indevida, o que não deve deixar de ser observado argutamente por advogados e operadores do direito em geral.

\section{O Código Civil de 1916 e a Transmissão Causa Mortis}

Sabe-se hoje que, em nosso direito, a morte, a transmissão da herança aos herdeiros e a abertura da sucessão acorrem no mesmo tempo (Veloso, 2008, p. 1949), inspirando-se no que vinha determinado no texto do Código Civil de 1916 (Código "Beviláqua"). ${ }^{7}$ Cabe saber, entretanto, a origem de inspiração do dito preceito.

A origem imediata dele seria o artigo 978 da Consolidação das Leis Civis, de Teixeira de Freitas: 'Na sucessão á intestado a posse civil dos fallecidos transmitte-se logo á seus herdeiros com todos os effeitos da posse natural, não sendo necessário que esta se-tome." (Freitas, 2003, p. 581)

${ }^{7}$ Art. 1572. Aberta a sucessão, o domínio e a posse da herança transmitem-se, desde logo, aos herdeiros legítimos e testamentários. (Código Civil de 1916) 
Já a mediata seria o próprio Princípio Saisine, com a sua origem medieval, como já foi analisado anteriormente neste trabalho. Quanto ao seu processo de inserção no direito brasileiro, resume categoricamente Zenio Veloso, como coautor do Código Civil Comentado, organizado por Ricardo Fiuza:

O princípio da saisine foi introduzido no direito português pelo Alvará de 9 de novembro de 1754, reafirmado pelo Assento de 16 de fevereiro de 1786. O Código Civil português, de 1867, já revogado, dizia no artigo 2011: "A transmissão do domínio e posse da herança para os herdeiros, quer instituídos, quer legítimos, dá-se no momento da morte do autor dela." (Veloso, 2008, p. 1949)

O mesmo autor atesta que o referido preceito foi abandonado no Código Civil português de 1966, o qual se filiou à legislação e doutrina italiana, fazendo-se correlação ao artigo 459 do Código Civil italiano de $1942^{8}$, em que a transmissão ficava à mercê de prévia aceitação, retroagindo os efeitos. No que pese a expressa determinação legal exposta, afirma Roberto de Ruggiero, acerca do momento da abertura da sucessão, do chamamento à herança e da aquisição da herança, o seguinte:

No direito civil italiano tais fatos verificam-se em regra, em nossa opinião, num único momento, e este é o da morte do de cujus. Pela morte abrese a sucessão e simultaneamente devolve-se a herança e a pessoa que a ela foi chamada adquire-a. Quem, pelo contrário, admite a possibilidade de sucessivos chamamentos e a necessidade de aceitação para a aquisição, deve separar o momento da aquisição daquele do chamamento e, no caso de chamamento sucessivo, o momento em que este se dá daquele da abertura da herança ou sucessão. (Ruggiero, 1999, p. 622.)

O que Ruggiero (1999, p. 622) quer expressamente dizer quando se refere à aquisição de herança é o fato de ela tornar-se do herdeiro, transmitir-se ao seu patrimônio a partir da abertura da sucessão, a qual se dá com a morte.

Em síntese, para concluir, é-nos válido expor a interpretação dada ao artigo 1572 do Código Civil de 1916 pelo seu próprio formulador, ao reafirmar o princípio Saisine, do Direito francês, do seguinte modo:

A sucessão hereditária abre-se com a morte do autor da herança. Desde esse momento, opera-se a transmissão da propriedade e da posse dos bens substituindo-se os sujeitos das relações jurídicas; no instante que precede a morte, o sujeito dessas relações jurídicas é o de cujus, no instante em que se segue à $[$ sic $]$ morte, o sujeito é o herdeiro. (1999, p. 622)

\footnotetext{
${ }^{8}$ Art. 459. Acquisto dell'eredità L'eredità si acquista con l'accettazione (Cod. Civ. 470 e seguenti, 586).
} L'effetto dell'accettazione risale al momento nel quale si è aperta la successione (Cod. Civ. 456, 1146). 


\section{[i. Visão Jurisprudencial do Assunto}

Assim se pronunciou, em 2009, o Superior Tribunal de Justiça

TRIBUTÁRIO -ITCD -FATO GERADOR -PRINCÍPIO DA SAISINE -SÚMULA 112/STF.

1. Cinge-se a controvérsia em saber o fato gerador do ITCD - Imposto de Transmissão Causa Mortis.

2. Pelo princípio da saisine, a lei considera que no momento da morte o autor da herança transmite seu patrimônio, de forma íntegra, a seus herdeiros. Esse princípio confere à sentença de partilha no inventário caráter meramente declaratório, haja vista que a transmissão dos bens aos herdeiros e legatários ocorre no momento do óbito do autor da herança.

3. Forçoso concluir que as regras a serem observadas no cálculo do ITCD serão aquelas em vigor ao tempo do óbito do de cujus.

4. Incidência da Súmula 112/STF. Recurso especial provido. ${ }^{9}$

O STJ apenas confirmou seguir entendimento passado do Supremo, o qual levou ao teor contido na Súmula $112^{10}$, no sentido de que o fato gerador do tributo se daria no momento da transmissão do patrimônio, que, no Brasil, se dá com a morte.

Assim também novamente se posicionou o STJ no ano de 2010, em decisão monocrática que teve como relator o ministro Humberto Martins. ${ }^{11}$

Como se pronunciou a professora Misabel Abreu Machado Derzi em atualização recente à obra Direito Tributário Brasileiro, de Baleeiro, "Como ressalta Aliomar Baleeiro, nas transmissões por causa da morte, o aspecto temporal da hipótese é a data do óbito, dia em que se considera aberta a sucessão. Por isso, os princípios constantes (não a redação literal) das Súmulas nos 112 e 113 são ainda válidos." (Baleeiro, 2010, p. 261)

No que concerne à visão do STJ em relação à possibilidade de correção monetária sobre o que fora avaliado, em recorrência à Súmula 113 do Supremo, desta forma foi redigida a ementa de decisão do tribunal em 2004, cujo relator foi o ministro Castro Meira:

9 STJ - RECURSO ESPECIAL: REsp 1142872 RS 2009/0104234-6, Julgamento: 20/10/2009, Ministro HUMBERTO MARTINS

${ }^{10}$ Assim é a redação da Súmula: "O imposto de Transmissão causa mortis é devido pela alíquota vigente ao tempo da abertura da sucessão."

${ }^{11}$ Com efeito, pelo princípio da saisine, com a abertura da sucessão, o domínio e a posse dos bens é transferida deimediatoaosherdeiros. OfatogeradordoITCMD(art.1572 do Códigode 1916eart.1784do Códigoatual) incide sobre os bens com a abertura da sucessão. Nesse momento (abertura da sucessão/morte do de cujus), ainda não é exigível o pagamento da exação. O art. 38 do Código Tributário Nacional é bastante claro ao estabelecer que a base de cálculo do imposto é o valor venal dos bens ou direitos transmitidos. Forçoso concluir que somente com a liquidação da herança, via sentença judicial, é que se definem quais os bens que efetivamente foram transmitidos aos herdeiros. Consequentemente, a obrigação tributária, existente desde a data do óbito, somenteéexigiveloseucumprimentoapósahomologaçãodocálculoporsentençajudicialtransitadaemjulgado. Nesse sentido é a Súmula 113/STF, que assim dispõe:" O imposto de transmissão causa mortis é calculado sobre o valor dos bens na data da avaliação" (STJ - PETIÇÃO DE RECURSO ESPECIAL: REsp 1195974, Relator(a): Ministro HUMBERTO MARTINS) 
TRIBUTÁRIO. IMPOSTO DE TRANSMISSÃO CAUSA MORTIS. SÚMULA 113/STF. CORREÇÃO MONETÁRIA. CABIMENTO.

1. "O imposto de transmissão causa mortis é calculado sobre o valor dos bens na data da avaliação" (Súmula 113/STF).

2. Não recolhido o valor na época própria, torna-se indispensável a necessária atualização do valor. É pacífico o entendimento de que a correção monetária da base de cálculo não implica alteração do fato gerador. Precedentes.

3. Recurso especial conhecido e improvido ${ }^{12}$

\section{A Personalização do Imposto Causa Mortis}

O tributo sucessorial foi, gradativamente, perdendo seu caráter de imposto indireto e impessoal e se foi tornando direto e pessoal com o tempo, ou seja, personalizando-se. Seguindo a orientação constitucional ${ }^{13}$, o imposto não é devido sem que o patrimônio tenha se distribuído entre os herdeiros, sendo analisado e graduado segundo a capacidade econômica do contribuinte, não podendo ser cobrado de pronto sobre o acervo hereditário ainda não partilhado entre os herdeiros, ou seja, não havendo prévia liquidação da herança.

Tal tendência da personalização influenciou cabalmente o momento da constituição do crédito tributário, o que influi, consequentemente, para se definir o instante a partir do qual se correria o prazo prescricional para ação de cobrança do tributo por parte da Fazenda Pública.

Quanto ao fenômeno da personalização propriamente dito, faz-se mister lembrar que a progressividade do imposto tem com ela relação íntima, sendo exemplos de sua adoção, além do Brasil, países como a Inglaterra, a Alemanha, os Estados Unidos, a França, dentre vários outros, o que nos leva a perceber a necessidade da progressividade como parâmetro para se levar em conta a capacidade econômica do indivíduo, baseando-se no valor dos bens herdados. A fim de se ter uma ideia mais abrangente sobre o fenômeno da personalização, faz-se indispensável referência a ensinamento imperecível acerca do tema, proveniente de palavras do mestre Aliomar Baleeiro:

Embora Nitti inclua o imposto sucessorial entre os indiretos, sua moderna utilização sobre os quinhões hereditários coloca-os entre os diretos e pessoais.

As legislações contemporâneas acentuam diferentes características da personalização atual desse tributo, especialmente quanto:

\footnotetext{
${ }^{12}$ STJ - RECURSO ESPECIAL: REsp 57742 PR 1994/0037618-9, Julgamento: 03/05/2004, Relator(a): Ministro CASTRO MEIRA

${ }^{13}$ Art. $145, \S 1^{\circ}$. Sempre que possível, os impostos terão caráter pessoal e serão graduados segundo a capacidade econômica do contribuinte, facultado à Administração Tributária, especialmente para conferir efetividade a esse objetivo, identificar, respeitados os direitos individuais e os termos da lei, o patrimônio, os rendimentos e as atividades econômicas do contribuinte.
} 
a) à descriminação pelo grau de parentesco (alíquotas menores entre descendentes, ascendentes e cônjuges; médias para colaterais e pesadas entre estranhos - cresce índice numérico de progressão à medida que se distancia o parentesco);

b) à isenção para pequenos quinhões, sobretudo se os herdeiros são órfãos, assim como para instituições filantrópicas;

c) às reduções para herdeiros de avançada idade ou que não são ricos;

d) à escala progressiva, segundo o vulto dos quinhões;

e) à agravação do tributo, se o herdeiro reside noutro estado ou no estrangeiro;

f) à possibilidade de encarar os encargos de família do defunto e do herdeiro para mitigação da tabela (lei francesa que estabeleça deduções quando o de cujus deixa vários filhos ou quando os tem numerosos o herdeiro). (Baleeiro, 2010, p. 261)

Observemos que o item "d", apontado por Baleeiro, tem parecido ser o mais comum nas legislações em geral, levando-nos a crer que esse parâmetro de majoração de alíquotas vem se apresentando mais equânime, à semelhança da sistemática do imposto sobre a renda.

Levando-se em conta todos esses aspectos, pelos quais se manifesta o fenômeno da personalização do imposto tratado e, conseguintemente, se pode apurar a dita capacidade econômica, vê-se-lhe inviabilizado o intento a partir do momento em que não se verificou a liquidação da herança, haja vista o temporário desconhecimento do sujeito passivo e da base de cálculo, fundamentais para sua realização.

Uma prova legislativa da personalização desse tributo, no próprio CTN, está na redação do parágrafo único de seu artigo 35, o qual prevê tantos fatos geradores quantos forem os herdeiros ou legatários, não deixando de ser contraditório ao Princípio Saisine.

\section{Decadência em Direito Tributário}

A decadência em nosso direito tributário é a perda do direito potestativo (já que independe da colaboração de terceiros ou da atuação do Judiciário) da Fazenda Pública de lançar. Não se deve esquecer que "A primeira finalidade do lançamento é constatar oficialmente que o fato gerador ocorreu." (Sousa, 1982, p. 103)

Há, no entanto, quem não o veja como um direito potestativo, mas como um dever do Estado, assim argumentando: "Trata-se, na verdade, de um dever do Estado, enquanto entidade tributante, que se não confunde com o direito subjetivo de exigir a prestação, não podendo ser considerado, também, como pretende importante segmento doutrinário, um direito potestativo." (Carvalho, 2007, p. 482)

Podemos diferenciar dois tipos de prazos decadenciais, a depender do tipo de lançamento previsto na legislação do tributo a ser cobrado. 
Se o lançamento previsto é por homologação, correrá o prazo de cinco anos, em regra, partindo do fato gerador do tributo. Alerte-se que o lançamento por homologação não se submete à decadência, haja vista que aquilo "que é passível de decadência é o lançamento de ofício, que cabe à autoridade realizar quando constate omissão ou inexatidão do sujeito passivo no cumprimento do dever de antecipar o pagamento do tributo." (Amaro, 2010, p. 433). Faz-se inviável ser de outra forma, pois, do contrário, estar-se-ia considerando subordinada a decadência à atitude do sujeito passivo da relação tributária, o que tiraria o caráter de direito potestativo da faculdade de a Fazenda lançar. O prazo aplicável está previsto no artigo 150, 4 do Código Tributário Nacional. A título de exemplificação, o ITCM será lançado por homologação no caso do inventário extrajudicial, previsto pela Lei 11.441 do ano de 2007.

Quando, porém, o lançamento previsto é o por declaração ou o de oficio, tem-se o caso previsto no artigo 173, I do CTN, no qual a regra é a contagem do prazo a partir do exercício financeiro posterior àquele em que se poderia realizar o lançamento, sendo também de cinco anos o período de sua contagem.

Por fim, assim como lembra Machado Segundo (2009, p. 89), tais prazos são incompatíveis entre si, excluindo-se um ao outro, já que correspondem a situações de fato completamente distintas uma da outra, no que pese serem ambos os prazos de caráter decadencial. Dessa forma, também alerta Ricardo Lobo Torres: "A decadência prevista no art. 173 não se confunde com a do art. 150, $\S 4$, do CTN, referente ao lançamento por homologação.” (Torres, 2005, p. 301)

\section{a O Prazo Decadencial no Imposto Sobre Herança}

$\mathrm{Na}$ análise do momento a partir do qual se correria o prazo decadencial, deve-se, de pronto, diferenciar o caso em que há pagamento antecipado do imposto do que não o antecipa, para efeitos de aplicação do artigo 173, I do Código Tributário Nacional (segundo caso) ou do artigo 150, 44 (primeiro caso) do referido código.

Por meio da argumentação desenvolvida por Clayton Eduardo Prado, podem-se diferenciar quatro situações para efeitos de decadência, quais sejam:

a) Em ausência do ajuizamento do processo ou da lavratura de escritura pública de inventário e partilha sem pagamento antecipado do tributo;

b) Em ajuizamento sob rito solene;

c) Em ajuizamento de arrolamento ou escritura pública de inventário e partilha, havendo pagamento antecipado do tributo;

d) Em ajuizamento de arrolamento sem apresentação de declaração do ITCMD e sem pagamento antecipado do tributo; 
Quanto ao primeiro caso, o melhor entendimento seria o que defende o início do transcurso do prazo a partir da realização do inventário e da partilha, visto que seria inconcebível o pensamento em contrário, já que não há lançamento sem prévio conhecimento da base de cálculo e do sujeito passivo, ligados, como visto, ao fenômeno de personalização do imposto.

Referindo-se ao segundo caso, para Clayton Prado não há de se falar de prazo decadencial, visto ser incompatível a existência de lançamento tributário. Isso se dá pelo fato de existir previsão de cálculo judicial que o substitui. Não há prazo, portanto, porque é "vedado ao titular do crédito efetuar o lançamento tributário." (Prado, 2009, p. 116)

Entendemos, no entanto, de forma diversa, ao defender que esse seria caso de lançamento por declaração, susceptível, portanto a prazo decadencial. Para ilustrar, pode-se referenciar a legislação do Estado do Ceará acerca do lançamento do ITCM, assim exposta: "Art. 12. O lançamento do imposto ocorre no momento da apuração do tributo pela autoridade fazendária." (Ribeiro Neto, 2011, p. 1158) Leve-se em consideração que é a lei tributária relativa a cada tributo que regula o lançamento, escolhendo modalidade adaptável a cada tributo (Sousa, 1982, p. 109). Há de se respeitar, portanto, a determinação da lei tributária, que não deve se restringir à atuação do judiciário.

O terceiro se refere a caso de lançamento por homologação ou autolançamento (Sousa, 1982, p. 109). ${ }^{14}$, encaixando-se no artigo 150, $\S 4$ do CTN, como já analisado. Clayton Eduardo defende que uma interpretação literal do referido dispositivo seria incoerente, já que se deveria considerar como marco inicial do prazo a ocorrência do fato gerador, ou seja, a transmissão na data da ocorrência da morte, abrindo-se a sucessão. Conforme suas palavras, "se a lei atribuiu ao particular o dever de apresentar declaração e recolher o imposto em certo prazo, não seria lógico que a autoridade administrativa pudesse efetuar o lançamento antes de esgotado esse prazo.” (Prado, 2009, p. 117)

Portanto, somente poderá correr o prazo decadencial se houver o prévio recolhimento do imposto e apresentação de sua declaração, a fim de se poder reajustar o valor pago. No que pese as conclusões desenvolvidas no decorrer do trabalho, invocando-se o Princípio Saisine, dando relevo à consideração do fato gerador do tributo no instante da morte para vários efeitos (alíquotas, questões processuais etc.), não seria compatível interpretar-se literalmente tal dispositivo devido à possível colisão e incompatibilidade dos prazos, gerando supressão do direito de lançar o tributo.

Quanto ao último caso, levando-se em conta a Súmula 114 do Supremo e sabendo que a homologação da partilha é vedada caso não haja

\footnotetext{
${ }^{14}$ No que pesem as críticas ao termo, por estar desconforme com a titularidade da Fazenda para a realização do lançamento, segundo nossa legislação.
} 
pagamento do ITCMD, o qual pressupõe a declaração do referido imposto, somente após a declaração poderá fluir o prazo decadencial.

\section{Considerações Finais}

Como se pode ver, toda discussão gira em torno de dois polos, o primeiro delimitando o fenômeno da personalização e o segundo se relacionando às repercussões práticas do reiteradamente citado Princípio Saisine. Ao mesmo tempo em que esses polos se contrapõem, eles se complementam nas soluções dos questionamentos propostos e uma análise sistêmica de nosso ordenamento jurídico se perfaz particularmente necessária no desenvolvimento do tema. A particularização dos casos concretos leva à conclusão de que dispositivos imediatistas e de reduzida abrangência são cada vez mais ineficientes no tratamento de situações práticas.

\section{REFERÊNCIAS}

AMARO, Luciano. Direito Tributário Brasileiro. 16 ed. São Paulo: Saraiva, 2010. BALEEIRO, Aliomar. Direito Tributário brasileiro. 11 ed. Rio de Janeiro: Forense, 2010.

. Uma Introdução à Ciência das Finanças. 17 ed. Rio de Janeiro: Forense, 2010.

BEVILÁQUA, Clovis. Código Civil dos Estados Unidos do Brasil Comentado. 4 ed. Rio de Janeiro: Livraria Francisco Alves, 1939. 6 v.

BRASIL. Código Civil. Disponível em: <http://www.planalto.gov.br/ccivil/ leis/2002/L10406.htm>. Acesso em: 19 abr. 2011.

BRASIL. Constituição (1998). Constituição da República Federativa do Brasil. Brasília, DF, Senado, 1988.

CARVALHO, Paulo de Barros. Curso de Direito Tributário. 18 ed. São Paulo: Saraiva, 2007.

CORREIA NETO, Celso de Barros. ITCM: um imposto sobre a morte. IN: MARTINS, Ives Gandra da Silva; BRITO, Edvaldo Pereira de (orgs.). Direito Tributário: impostos estaduais. São Paulo: Revista dos Tribunais, 2011. 4 v.

DINIZ, Maria Helena. Curso de Direito Civil brasileiro: direito das sucessões. 19 ed. São Paulo: Saraiva, 2005. 6 v.

FREITAS, Augusto Teixeira de. Consolidação das leis civis. Brasília: Senado Federal, 2003. 
KEYNES, John Maynard. A teoria Geral do Emprego do Juro e da Moeda. Trad. de Mário R. da Cruz. 1 ed. São Paulo: Atlas, 1982.

MACHADO, Hugo de Brito. Curso de Direito Tributário. 31 ed. São Paulo: Malheiros, 2010.

MACHADO SEGUNDO, Hugo de Brito Machado. Processo Tributário. 4 ed. São Paulo: Atlas, 2009.

. Direito Financeiro e Tributário. 5 ed. São Paulo: Atlas, 2010.

MACHADO, Schubert. AAlíquota Máxima Do Imposto De Transmissão Causa Mortis E Doação No Estado Do Ceará. Disponível em: < http://www.machado.adv.br>. Acesso em: 20 abr. 2011.

MIRANDA, Pontes de. Tratado de direito privado. Rio de Janeiro: Borsoi, 1968. PRADO, Clayton Eduardo. Imposto sobre Herança. 1 ed. São Paulo: Verbatim, 2009. RIBEIRO NETO, José. Direito Tributário \& Legislação Tributária do Estado do Ceará. 4 ed. Fortaleza: Fortes, 2011.

RIPERT, Georges; BOULANGER, Jean. Tratado de derecho civil: segun el tratado planiol, sucessiones. Buenos Aires: La Ley, 1963/1965. 1 v. Tomo X.

RUGGIERO, Roberto. Instituições de Direito Civil: Direito das Obrigações, Direito Hereditário. 1 ed. Campinas: Bookseller, 1999. 3 v.

SOUSA, Rubens Gomes. Compêndio de Legislação Tributária. 4 ed. (póstuma) São Paulo: Resenha Tributária, 1982.

TORRES, Ricardo Lobo. Curso de Direito Financeiro e Tributário. 12 ed. Rio de Janeiro: Renovar, 2005.

VELOSO, Zenio. Do Direito das sucessões. Livro V. IN: FIUZA, Ricardo (org.). Código Civil Comentado. 6 ed. São Paulo: Saraiva, 2008.

\section{TEMPORARY CRITERION OF INHERITANCE TAX}

Abstract: The present work focuses on the temporary criterion which determines the generating fact of the inheritance tax according to Brazilian law, considering the saisine principle.

Keywords: Tax law. Tax. Inheritance. Generating fact. Temporary criterion.

Data de recebimento: jan/2011 - Data de aprovação: mar/2011 